\title{
Yawning As a New Potential Diagnostic Marker for Neurological Diseases
}

\section{Abstract}

Yawning apparatus and exact location of the yawn reflex remains controversial. Yet yawning is a significant behavioural response and potentially a new diagnostic marker of neurological disease. Association between cortisol, electromyography (EMG) and yawning was found in humans supporting Thompson Cortisol Hypothesis (TCH) which complements thermoregulation hypotheses indicating brain cooling occurs when yawning. 28 male, 54 female volunteers, 18-69 years, randomly allocated to experimentally controlled conditions of provoked yawning. Saliva samples were collected at start and after yawning, or after stimuli presentation, in absence of yawning. EMG data was collected from jaw muscles at rest and after yawning. Specially designed yawning susceptibility scale, Hospital Anxiety and Depression Scale, General Health Questionnaire, demographic, health details were collected. Between- and within-subjects comparisons of yawners and nonyawners was conducted. Exclusion criteria: chronic fatigue, diabetes, fibromyalgia, heart condition, high blood pressure, hormone replacement therapy, multiples sclerosis, stroke. Yawning group: significant difference between saliva cortisol samples, rest and yawning $\mathrm{t}(37)=2.842, \mathrm{p}=0.007$, compared with non-yawners, rest and post-stimuli, which was non-significant. Yawners, rest EMG: -100 to 200 millionth of a volt (mean=182.2) and -60000 to 18000 (mean=3 897.4) after yawning. Non-yawners, rest EMG: -80 to 120 (mean=37.2) and -400 to 800 (mean=57.5) after stimuli presentation. Yawners showed larger peak following yawn compared with post-stimuli for non-yawners. Significant supporting evidence for $\mathrm{TCH}$ suggests cortisol levels are elevated during yawning. Changes in cortisol levels may become a new diagnostic tool in early diagnosis of neurological symptoms. Bournemouth University Research \& Ethics BU-KAPP06-09/13.

Keywords: Biomarker; Cortisol; Diagnosis; Electromyography; Neurological disorder; Yawning

Received: August 22, 2015; Accepted: October 02, 2015; Published: October 05, 2015

\section{Introduction}

The first yawn of the day is usually when we awake to stretch our intercostal muscles surrounding our lungs to bring in more oxygen. Many of us recognise yawning as a sign of tiredness or boredom yet we also yawn before that important job interview. We contagiously yawn when our pets yawn and because we are empathetic towards another yawning human being and therefore, most of us can relate to yawning.

Yet the physiological apparatus and exact location of our yawning response is uncertain. So much so, that yawning has been the

\section{Simon B N Thompson ${ }^{1,2^{*}}$ and Mia Simonsen ${ }^{1}$}

1. Psychology Research Centre, Bournemouth University, Talbot Campus, Poole House (P305), Poole, BH12 5BB, UK;

2. International Scientific Council for Research, Université Paris X Ouest Nanterre La Défense, 200 avenue République, 92001 Nanterre, France

Corresponding author:

Simon B N Thompson

\section{”simont@bournemouth.ac.uk}

Associate Professor, Psychology Research Centre, Bournemouth University, Talbot Campus, Poole House (P305), Poole, BH12 5BB, UK..

Tel:+441202961558

Citation: Thompson SBN, Simonsen M. Yawning As a New Potential Diagnostic Marker for Neurological Diseases. J Neurol Neurosci. 2016, 6:3. 
is also associated with excessive yawning and a rise in brain temperature, governed by a small structure in the top of the brain, the hypothalamus $[3,4]$

Temperature regulation and circadian rhythm is the responsibility of the hypothalamus which is intimately linked to two other body structures, the pituitary gland, also situated in the brain, and the adrenal glands which secrete adrenaline. The hypothalamuspituitary-adrenal (HPA) axis helps us produce enough hormones to protect against stress and provides us with readiness for physical activity.

Yawning is exhibited in many different situations and it is because of this that it has made yawning so difficult to research resulting in its origin being so allusive. Anecdotally, yawning has been seen in response to migraine headaches; following excessive fatigue or sleepiness [5]; after ingesting "magic mushrooms" whose active ingredient is psilocybin; following taking the antidepressant Prozac; after an anxiety or panic attack; after seeing images of animals and humans yawning; after reading an article about yawning!

The link between excessive yawning and neurological disease has been noted elsewhere. For example, Lana-Peixoto, et al. [6] found that excessive yawning was the presenting symptom of five patients with neuromyelitis optica spectrum disorders (NMOSD). Brain MRI was abnormal and most frequently showed brainstem and hypothalamic lesions. The authors conclude that pathological yawning may be a neglected although not a rare symptom in NMOSD. Excessive yawning is also noted in adrenal insufficiency [7]; this is thought to occur because of an irregulation of adrenaline and cortisol, both actively involved in the HPA-axis. It is probable that other neurological diseases such as Parkinson's disease and Motor Neurone Disease may also be implicated in the HPA feedback loop.

The Thompson Cortisol Hypothesis [8] is the first evidence-based report that links the naturally produced protective "stress" hormone, cortisol, with yawning, and demonstrates that cortisol rises when we yawn. Produced by the zona fasciculate of the adrenal cortex within the adrenal gland [7], it is suggested that the rise in cortisol level triggers our yawning response. Implications of this research are that yawning is an important mechanism for controlling hormone regulation and hypothalamus temperature regulation.

Physicians working in the rehabilitation of stroke patients have reported on significant findings from yawning stroke patients [9]. Sir Francis Walshe, a British neurologist, first reported on patients with lesions in the brain stem region who could raise their paralyzed arm when spontaneously yawning [10]. This has been evidenced since and consistently, by others [11-13] and particularly, in patients with left hemiplegia, the yawning response has been attributed to pseudobulbar syndrome [14]. Swallow reflex and yawning have been postulated to be temporally related in a study that considered gape, smile and yawning responses [15]. Participants were observed to swallow directly after yawning; again suggesting that the brain stem region might be the commonality between both reflexes. Findings supporting the presence of common neuroanatomico- physiological pathways for spontaneous swallows and yawning have also been reported [16].

Mental Attribution Theory $[17,18]$ has been presented as the reason for us contagiously yawning as we seem to be empathic to others who yawn, especially when we perceive our belonging to a particular social grouping and yet it seems that yawning is so important to our maintenance and regulation that it does not wait until we are born. In fact, it happens in the womb [19].

Consistent reports have shown photographic evidence of yawning in the foetus, reinforcing the fact that it is one of the first crucial developments we make. New-born babies yawn more frequently than toddlers do, since sleep deprivation increases the chances of us yawning and makes us more susceptible to the effects of stress and fatigue [20].

Yawning is not confined to humans either, with most vertebrates experiencing yawning perhaps because of the need to raise arousal and the level of alertness. Universal yawning seems to be found in vertebrates in association with arousal but also with sleep, hunger and satiety [21]. 'Emotional yawning' has been reported in animals visiting the veterinary surgeon, in elite athletes and actors before performing, and in parachutists about to jump [22].

From fMRI studies, communicative yawning, such as in contagion, appears to involve the frontal and parietal lobes, insula and amygdala [23-25], and has been postulated to be related to the mirror-neuron system [26]. Interestingly, temperature contagion has been evidenced in participants observing and rating others whose hands were immersed in ice cold water [27]. Hence, it is possible that yawning and temperature, seen to be linked in conditions such as MS, may also be subject to contagion and empathy.

Regardless of the function of the yawn, it is probable that the critical threshold level of cortisol is reached because of fatigue, empathy, or sleep deprivation, to elicit the yawning response. Electromyography (EMG) activity in the jaw muscles is increased which in turn regulates the further production of cortisol and also of adrenaline from the adrenal glands [28]. Feedback via the HPA-axis continues to regulate cortisol and adrenaline production within the closed loop.

\section{Materials and Methods}

82 volunteers ( 28 male, 54 female) aged between 18-69 years were recruited from students and the research volunteer pool at Bournemouth University using the computerised recruitment system (SONA), and Facebook. All participants were properly consented according to code of conduct and research guidelines, and exposed, under randomised controlled trials guidelines, to three conditions intended to provoke a yawning response-photos of people yawning; boring text about yawning; short video of person yawning. Comparisons were made with people exposed to the same conditions but who did not yawn.

Saliva samples were collected at start and again after yawning response, together with electro-myographical data of the jaw muscles to determine rest and yawning phases of neural activity. If there was no yawning response, then a second saliva sample was taken at the end of the experimental paradigm. Cortisol levels 
are easily detected in saliva and it is a far less intrusive method than intravenous collection. Presence of cortisol in saliva is highly correlated with blood assay and it is also cheaper to analyse in the laboratory. A yawning susceptibility scale (questionnaire designed for this study), Hospital Anxiety and Depression Scale (HADS) [29,30], General Health Questionnaire GHQ28 [31-33] and demographic and health details were also collected from each participant.

Exclusion criteria were: chronic fatigue, diabetes, fibromyalgia, heart condition, high blood pressure, hormone replacement therapy, multiples sclerosis, and stroke. Between- and withinsubjects comparisons were made using t-tests and correlations using the SPSS package [version 22]. This enabled a comparison to be made between yawner and non-yawner participants as well as between rest status and yawning episodes.

\section{Results}

The mean age of participants was 27.3 ( $s d=10.42$ ). There were no significant differences between groups in terms of age, HADS anxiety and depression scores, and GHQ28 scores.

Normative data for saliva cortisol is known, and lies within the following ranges: (i) Morning collection is 3.7-9.5 nanograms (one billionth of a gram or $10^{-9}$ ) per millilitre of saliva; (ii) Noon collection is 1.2-3.0 nanograms per millilitre; (iii) Evening collection is 0.6-1.9 nanograms per millilitre.

In saliva cortisol sample 1, the means for non-yawners was 2.1 ( $s d=1.67)$, and for yawners was 2.6 ( $s d=1.99)$. In sample 2, the means were 2.2 ( $s d=1.72$ ) for non-yawners, and 3.1 ( $s d=2.26)$ for the yawners. Hence, the yawners had higher levels of resting and post-experiment saliva cortisol levels than the non-yawners.

There were no significant differences between sample 1 (saliva cortisol) and sample 2 (saliva cortisol) for those who did not yawn during the experiment. This was confirmed using a repeatedmeasures t-test: $\mathrm{t}(41)=-.831, \mathrm{p}=.411$. However, there was a significant difference between sample 1 (saliva cortisol) and sample 2 (saliva cortisol) amongst the yawners: $t(37)=2.842, p=.007$ (Figure 1).

Using analysis of variance (ANOVA), there was high significance between the groups when comparing sample 2 (saliva cortisol), indicating that non-yawners differed significantly from yawners in their cortisol levels, $F(1,78)=4.454, p=.038$ (Figure 2).

For the yawners, at rest, the EMG range was -100 to 200 millionth of a volt (mean of 182.2) as compared with -60000 to 18000 (mean of 3897.4 ) after yawning. For non-yawners, the range was -80 to 120 (mean of 37.2) and -400 to 800 (mean of 57.5) after the stimuli presentation. Therefore, the yawners tended to show a larger peak following the yawn as compared with the non-yawners, post-stimuli. Absolute means were also much higher for the yawners. There was a difference in EMG peak readings (EMG2HI) between the yawners and non-yawners, using t-test: $t(74)=2.2124, p=.037$ (Figure 3).

ANOVA was used to analyse EMG readings at rest and after yawning (or post-stimuli for the non-yawners). The minimum reading at rest (EMG1LO) for the yawners was significantly higher than for the non-yawners $(p=.040)$. The peak reading at rest (EMG1HI) was also significantly higher than for the non-yawners

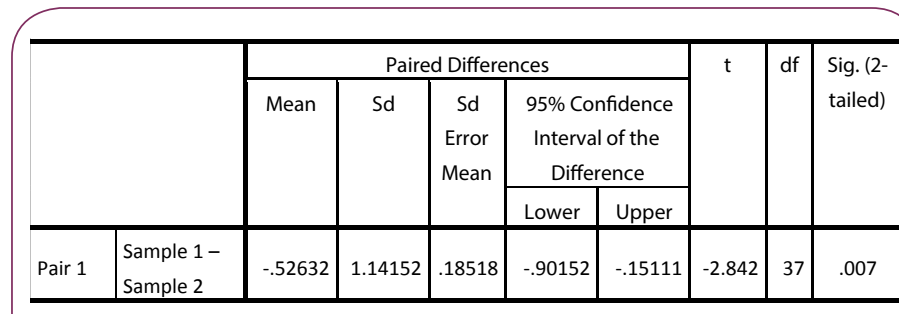

Figure 1 Cortisol - paired comparisons of yawners.

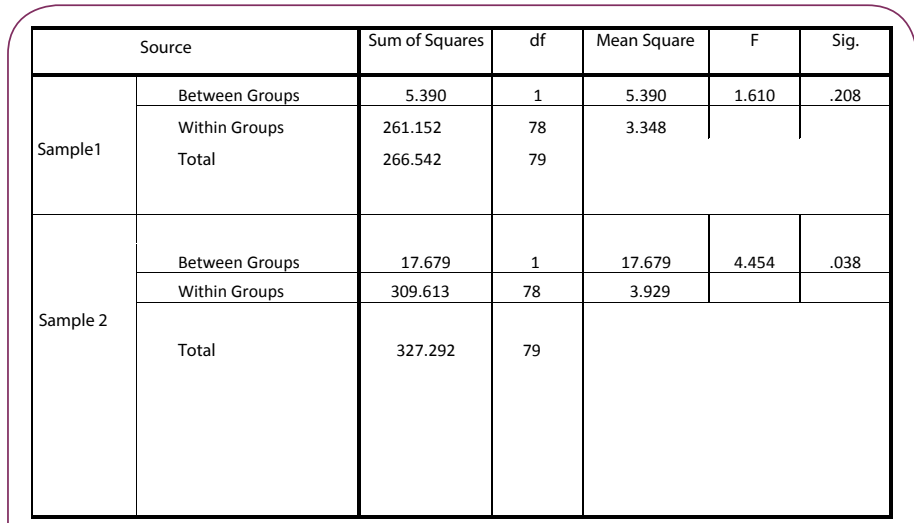

Figure 2 Cortisol - between-group effect.

( $p=.033)$ (Figure 4).

The peak reading after yawning (EMG2HI) was again significantly higher compared with the non-yawners $(p=.037)$; although the minimum reading after yawning and post-stimuli (for the nonyawners) was not significantly different $(p=.112)$ (Figure 5$)$. This suggest that the yawners showed significantly higher EMG levels both at rest and at peak after yawning but started from similar minimum EMG levels at the start of the yawning "EMG envelope", categorised by Thompson [28].

Yawning susceptibility scores were not normally distributed and did not show significant differences between the two groups, perhaps due to insufficient sensitivity of the measure.

\section{Power and effect size}

Power and effect sizes were computed based on repeated measures t-tests for both the yawning and non-yawning group.

\section{Discussion}

There are several interesting findings of this study, which are consistent with the Thompson Cortisol Hypothesis. Significant difference in saliva cortisol levels for those who yawned, between sample one and sample two, were found, which lends support for the hypothesis. No significant difference was found for the nonyawners between saliva cortisol sample 1 and sample 2. EMG activity also increased with elevated cortisol levels and when yawning.

Small (non-significant) rises in saliva cortisol levels in the nonyawners (between rest and post-stimuli) may be explained in terms of the experimental procedure. Since two time points of saliva cortisol sampling were taken for both groups, it is possible 


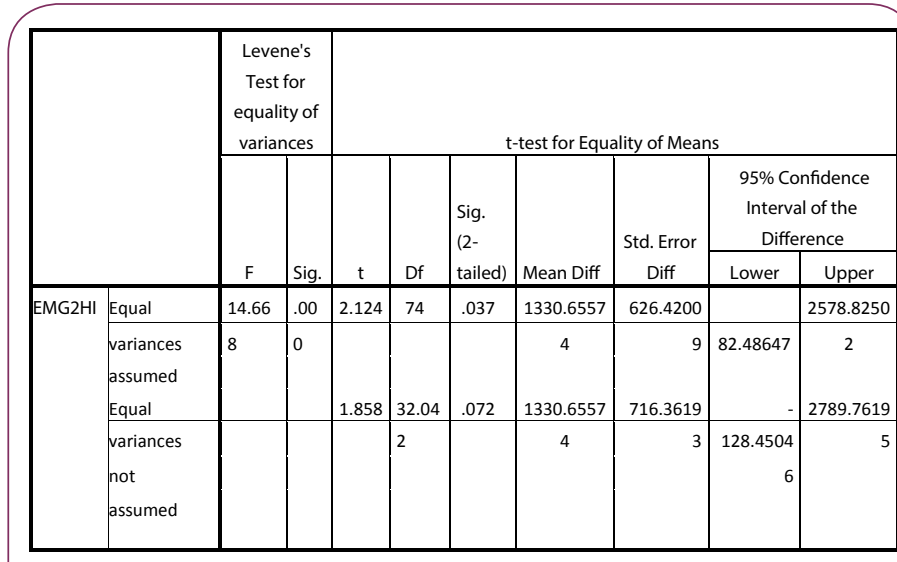

Figure 3 EMG peak means of total group.

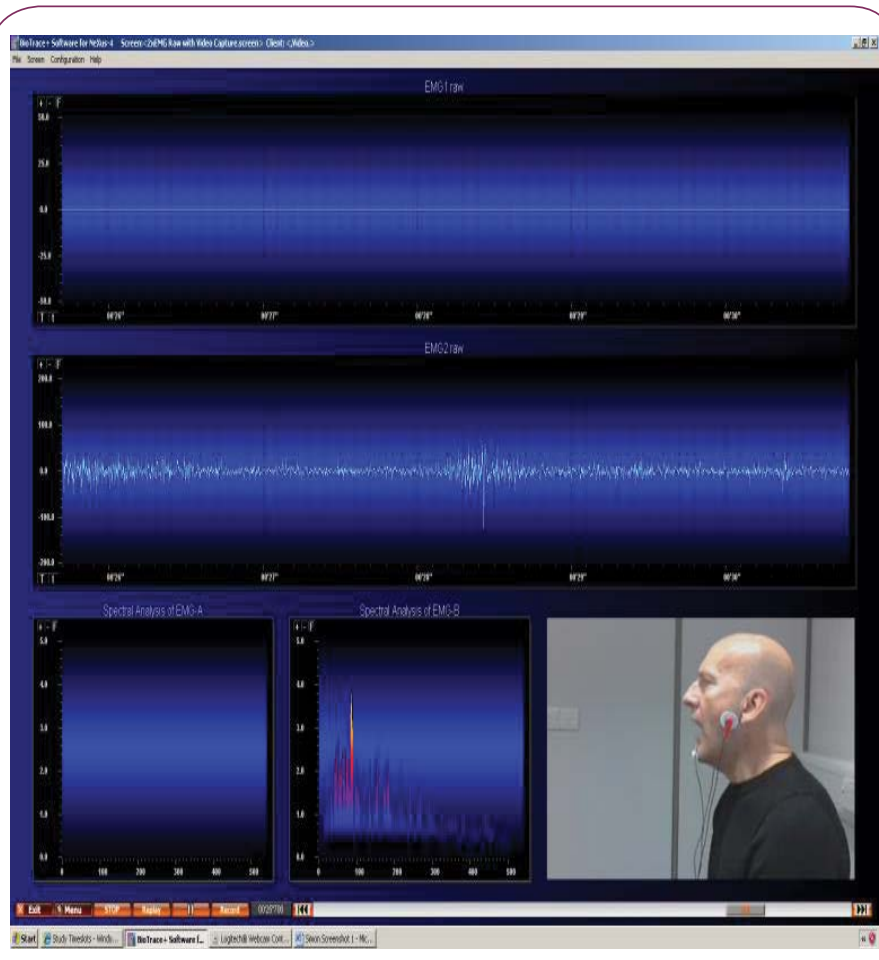

Figure 4 EMG trace showing EMGLO (min) and EMGHI (peak).

that cortisol levels rose for both groups in the presence of yawnstimuli but for the yawners, cortisol levels reached the threshold necessary for the elicitation of a yawning response. Previous studies have not consistently focused on repeat sampling which provides the advantage of indicating change in cortisol levels.

Neurological diseases are complicated because they present with different ranges of symptoms and severity. However, it is intriguing that diseases are often exacerbated by stress and thus by fluctuation in cortisol and adrenaline levels. Since both naturally occurring hormones are involved intimately in the body's HPA-axis, it is probable that they also play a part in regulating the effects of neurological disease. Other researchers have alluded to the fact that a common symptom in several neurological conditions and diseases is excessive yawning. For example, in multiple sclerosis, fatigue often gives rise to excessive yawning together with brain

\begin{tabular}{|l|l|r|r|r|r|l|}
\hline \multicolumn{2}{|c|}{} & \multicolumn{1}{|c|}{ Sum of Squares } & \multicolumn{1}{c|}{ df } & Mean Square & F & Sig. \\
\hline \multirow{3}{*}{ EMG1LO } & Between Groups & 76876.817 & 1 & 76876.817 & 4.389 & .040 \\
\cline { 2 - 8 } & Within Groups & 1296292.872 & 74 & 17517.471 & & \\
\cline { 2 - 8 } & Total & 1373169.689 & 75 & & & \\
\hline \multirow{3}{*}{ EMG2LO } & Between Groups & 129155009.111 & 1 & 129155009.111 & 2.580 & .112 \\
\cline { 2 - 8 } & Within Groups & 3704692667.586 & 74 & 50063414.427 & & \\
\cline { 2 - 8 } & Total & 3833847676.697 & 75 & & & \\
\hline \multirow{3}{*}{ EMG1HI } & Between Groups & 102093.181 & 1 & 102093.181 & 4.746 & .033 \\
\cline { 2 - 8 } & Within Groups & 1591830.371 & 74 & 21511.221 & & \\
\cline { 2 - 8 } & Total & 1693923.552 & 75 & & & \\
\cline { 2 - 8 } & Between Groups & 33059800.529 & 1 & 33059800.529 & 4.512 & .037 \\
\cline { 2 - 8 } & Within Groups & 542165500.861 & 74 & 7326560.822 & & \\
\cline { 2 - 8 } & Total & 575225301.390 & 75 & & & \\
\hline
\end{tabular}

Figure 5 EMG rest versus post-stimuli means of total group.

temperature rise ${ }^{3}$. In brain-stem ischaemic stroke, patients who excessive yawn are seen to execute an involuntary rise of their affected "paralyszed" arm [11,13]. In Parkinson's disease, it is has been long considered to be effective to regulate serotonin as well as dopamine levels, and it is possible that cortisol levels may also have an interaction with the overall homeostasis of hormones $[4,7,8]$. The Thompson Cortisol Hypothesis provides an explanation for excessive yawning, and links cortisol with this reflex behaviour. The extent to which they are involved in each neurological disease and condition is yet to be investigated.

It is understood that cortisol acts to protect our body against stress and plays a role in the regulation and balance of hormones released within the HPA-axis. The yawn response may give rise to an increase in cortisol levels to provide symptom relief such as in lowering brain temperature as proposed by Gallup [3]. This may be the mechanism involved in the excessive yawning of people with multiple sclerosis via the hypothalamus as temperature regulator.

To understand the extent to which brain temperature may be regulated by the hypothalamus would require temperature monitoring around the surface of the skull together with induced fatigue paradigms to discern threshold levels of cortisol release. The author is leading a team in the UK and in France (Université Paris X Ouest Nanterre La Défense; Hôpital Universitaire Amiens; and Jules Verne Université de Picardie) to conduct a series of fMRI studies involving people with multiple sclerosis to analyse fatigue, temperature moderation and yawning-cortisol response. It is hoped that this with further our limited knowledge of the complex yet intriguing mechanism that we see as simply yawning.

\section{Conclusions}

Yawning and cortisol is of interest to clinical scientists, practitioners, neurologists and neuroscientists. Whilst still presenting a scientific conundrum, it has presented as a fascination for centuries but is now emerging with potential clinical and neuro-scientific importance, especially in the domain of diagnostic biomarkers. Clearly, further research is indicated; particularly, mapping the frequency and variance in cortisol levels in different neurological diseases. 
However, it is fitting that this ancient mechanism, common to most of us that has been reported for many centuries, is perhaps a breakthrough for modern neuroscience and rehabilitation.

\section{Ethics}

Bournemouth University Research \& Ethics approval granted: BU-KAPP06-09/13. Protective measures were put in place for collection and analysis of saliva samples; data collected was made anonymous and the right of participants to withdraw from the study was upheld.

\section{Funding}

This research received funding of $£ 10000$ from the host institution, Bournemouth University, UK, to support the purchase of equipment and the analysis of samples.

\section{Competing interests}

None. 


\section{References}

1 Vigier MJ (translated by): Les aphorismes d'Hippocrate. Lyon, France: J-A Huguetan 1620.

2 Fleming WE, Pollak CP (2005) Sleep disorders in multiple sclerosis. Sem Neurol 25: 64-68.

3 Gallup AC, Gallup JrGG (2007) Yawning as a brain cooling mechanism: Nasal breathing and forehead cooling diminish the incidence of contagious yawning. Evol Psychol 1: 92-101.

4 Thompson SBN (2010) The dawn of the yawn: is yawning a warning? Linkin neurological disorders. Med Hyp 75: 630-633.

5 Catli T, Acar M, Hanci D, Arikan OK, Cingi C (2014) Importance of yawning in the evaluation of excessive daytime sleepiness: a prospective clinical study. Europ Arch Otorhinolaryngol.

6 Lana PM, Callegaro D, Talim N, Talim LE, Pereira SA (2014) G. Pathologic yawning in neuromyelitis optica spectrum disorders. $M$ S Rel Dis 3: 527-532.

7 Schillings WJ (2008) Physiology and tests of adrenal cortisol function. Glob Lib Wom Med Thompson SBN.

8 Medical Hypotheses (2014) Yawning, fatigue, and cortisol: expanding the Thompson Cortisol Hypothesis 4: 494-496.

9 Kang P, Dhand A (2015) Teaching video neuroimages: movement of a paralyzed arm with yawning. Am Acad Neurol e118.

10 Provine R (2012) Curious behavior: yawning, laughing, hiccupping and beyond. Belknap, New York, USA 31-32.

11 Wimalaratna HSK, Capildeo R (1988) Is yawning a brain stem phenomenon? Lancet 331: 8580:300.

12 Walusinski O (2007) Can stroke localisation be used to map out the neural network for yawning behaviour? J Neurol Neurosurg Psych 78: 1166.

13 Walusinski O, Neau JP, Bogousslavsky J (2010) Hand up! Yawn and raise your arm. Int J Stroke 5: 21-27.

14 Alajouanine Th, Thurel R (1932) Facial diplegia cerebral cortical form of pseudobulbar palsy. Rev Neurol 38: 516-517.

15 Kimiko A, Weisz S, Dunn R, DiGioacchino M, Nyentap J, et al. (2014) Occurrences of yawn and swallow are temporally related. Dysphag.

16 Ertekin C, Bulbu NG, Uludag IF, Tiftikcioglu BI, Arici S, et al. (2015) Electrophysiological association of spontaneous yawning and swallowing. Exp Brain Res.

17 Prasad $\mathrm{H}$ (2008) Yawning and why yawns are contagious: a theory on evolution and atavism. Med Hyp 2: 307-325
18 Sarnecki J (2008) Content and contagion in yawning. Phil Psychol 6: 721-737.

19 Reissland N, Francis B, Mason J (2012) Development of fetal yawn compared with non-yawn mouth openings from 24-36 weeks gestation. PloS ONE.

20 Giganti F, Hayes MJ, Cioni G, Salzarulo P (2007) Yawning frequency and distribution in preterm and near term infants assessed throughout 24-h recordings. Inf Beh Dev 30: 641-647.

21 Zilli I, Giganti F, Salzarulo P (2007) Yawning in morning and evening types. Phys Beh 91: 218-222.

22 Guggisberg AG, Mathis J, Schnider A, Hess CH (2011) Why do we yawn? The importance of evidence for specific yawn-induced effects. Neurosci Biobeh Rev 5: 1302-1304.

23 Norscia I, Palagi E (2011) Yawn contagion and empathy in Homo sapiens. PLoS One 6: e28472.

24 Platek SM, Critton SR, Myers TE, Gallup GG (2003) Contagious yawning: the role of self-awareness and mental state attribution. $\mathrm{Cog}$ Brain Res 17: 223-227.

25 Krestel H, Weisstanner C, Hess C, Bassetti C, Nirkko A, et al. (2013) Insular and caudate lesions release abnormal yawning in stroke patients. Brain Struct Funct.

26 Schurmann M, Hesse MD, Stephan KE, Saarela M, Zilles K, et al. (2005) Yearning to yawn: the neural basis of contagious yawning. Neuroimage 24: 1260-1264.

27 Cooper E, Garlick J, Featherstone E, Voon V, Singer T, et al. (2014) You turn me cold: evidence for temperature contagion. PLoS ONE: 1-10.

28 Thompson SBN (2013) How to catch a yawn: initial observations of a randomized controlled trial. Neurol 8: 1-8.

29 Snaith RP, Zigmond AS (1994) Hospital Anxiety and Depression Scale. Acta Psy Scand 67: 361-370.

30 Abiodun OA (1994) A validity study of the Hospital Anxiety and Depression Scale in general hospital units and a community sample in Nigeria. B J Psy 165: 169-172.

31 Goldberg D (1978) Manual of the General Health Questionnaire. $3^{\text {rd }}$ Edn, Windsor, NFER: England.

32 Goldberg D (1986) Use of the General Health Questionnaire in clinical work. BMJ 293: 1188-1189.

33 Bridges KW, Goldberg D (1986) The validation of the GHQ28 and the use of the MMSE in neurological in-patients. B J Psy 148: 548-553. 